Transport

Rail track costs management for efficient railway charges

Calvo, de Oña, López, Garach and de Oña
Proceedings of the Institution of Civil Engineers

http://dx.doi.org/10.1680/tran.11.00001

Paper 1100001

Received 03/01/2011 Accepted 15/04/2011

Keywords: economics \& finance/maintenance \& inspection/railway systems

\title{
Rail track costs management for efficient railway charges
}

1 Francisco Calvo PhD

Associate Professor, TRYSE Research Group, Department of Civil Engineering, University of Granada, ETSI Caminos, Granada, Spain

2. Juan de Oña PhD

Associate Professor, TRYSE Research Group. Department of Civil Engineering, University of Granada, ETSI Caminos, Granada, Spain

3. Griselda López BEng

Researcher, TRYSE Research Group. Department of Civil Engineering, University of Granada, ETSI Caminos, Granada, Spain
4 Laura Garach BEng

Lecturer, TRYSE Research Group. Department of Civil Engineering, University of Granada, ETSI Caminos, Granada, Spain

5 Rocío de Oña BEng

Researcher, TRYSE Research Group. Department of Civil Engineering, University of Granada, ETSI Caminos, Granada, Spain
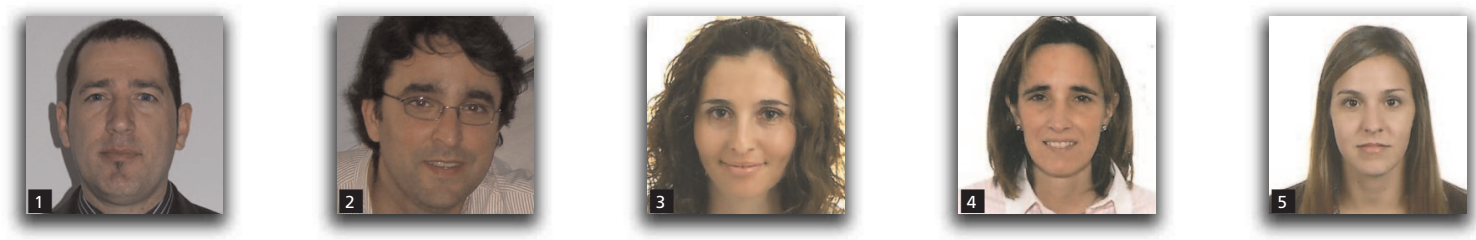

A part of track maintenance costs is directly related to train traffic, and therefore they are marginal costs in the short term. Track renewal costs over a longer period of time also increase with traffic, so they could be considered longterm marginal costs. Many different problems can arise when applying maintenance and renewal costs to railway undertakings. With regard to the costs as such, problems arise with their magnitude, the availability and quality of data, and the service life of maintenance and renewal operations. With regard to transferring costs, problems are related to cost recovery, the relationship between track charges and the costs they intend to recover, and the level of the service the infrastructure manager gives the railway operator. A system based on a differentiated approach to maintenance cost and renewal cost depreciation is proposed as a tool for track cost processing. Cost planning and the subsequent levying the costs on railway undertakings are both based on a single concept: the theoretical traffic load. Track usage charges that promote improvements in the activity of infrastructure managers and railway undertakings alike are arrived at by combining the differentiated approach to depreciation, the theoretical traffic load, actual cost data and short-term traffic estimates.

\section{Notation}

GTK gross-tonne-km

$t \quad$ life cycle of the renewal

$t_{i} \quad$ life cycle of the ' $i$ ' corrective maintenance operation

$t_{j}{ }^{\mathrm{e}} \quad$ estimated life cycle

$M_{i} \quad$ cost of the ' $i$ ' corrective maintenance operation

$R \quad$ renewal cost

E\&U enhancement and upgrading cost

$m_{\mathrm{p}} \quad$ annual cost of the preventive maintenance

$m_{k} \quad$ annual cost associated to corrective maintenance operations during any ' $k$ ' year

$r_{k} \quad$ annual cost associated to renewal operations during any ' $k$ ' year

$D_{\max }$ maximum deterioration allowed

$T_{\mathrm{f}} \quad$ theoretical traffic load

$S \quad$ coefficient that increases from 1.00 for speeds under $60 \mathrm{kph}$ up to 1.50 for speeds above $250 \mathrm{kph}$

$T_{\mathrm{V}} \quad$ weight in tonnes of the passenger cars

$K_{\mathrm{t}} \quad$ coefficient allowing for the traction-motor axle wear factor, and is equal to $1 \cdot 40$

$T_{\mathrm{tv}} \quad$ weight in tonnes of the tractive unit, in passenger trains

$K_{\mathrm{m}} \quad$ coefficient allowing for the influence of the axle-loads of freight wagons. Increases from $1 \cdot 15$ to 1.45 with the axle-load

$T_{\mathrm{m}} \quad$ gross tonnes hauled, in freight trains

$T_{\mathrm{tm}} \quad$ weight of the locomotive in freight trains.

\section{Introduction}

Track maintenance and renewal costs arise from wear and tear from train traffic and the context in which the track is placed. As a rule, maintenance operations are defined as small-scale operations (e.g. ballast compacting, track levelling and alignment, and rail grinding) that have a short life cycle (1-5 years). The purpose of the operations is to ensure a certain level of quality, reliability and safety. Therefore, maintenance costs tend to be considered as short-term marginal costs. 


\section{Offprint provided courtesy of www.icevirtuallibrary.com Author copy for personal use, not for distribution}

Prolonged exposure to adverse conditions (e.g. rain, frost, and rust) and, above all, wear and tear and deformations of track parts (e.g. rails, fastenings, sleepers, and ballast) caused by traffic require more frequent maintenance operations. On the other hand, the cost of each maintenance operation tends to be higher than the previous one, since the pace of a track's wear and tear increases with the accumulated amount of traffic it has supported. The result is a gradual increase in maintenance costs.

Railway track elements need to be changed every now and then (every 25-40 years) to prevent an uncontrolled increase in maintenance costs. This is what is known as renewal. Renewal costs refer to the replacement of such elements so the track's performance will remain the same as in the past (normally, when it was new or at the time of the last renewal). Therefore, renewals are much less frequent than ordinary maintenance operations, they cost more and their life cycle is longer. These features are more associated with long-term marginal costs.

According to the above, as train traffic gives rise to maintenance and renewal costs, the cost generated by running an additional train would be defined as a marginal cost (short-term for maintenance costs and long-term for renewal costs).

This direct relationship with traffic and Directive 2001/14/EC's support for the recovery of marginal costs generated by train traffic are the reason why, in practice, all current European charging systems include maintenance costs. Very few charging systems expressly indicate that they are including renewal costs. One exception is the UK, which has a variable track usage charge for recovering renewal costs. The decision as to whether or not to include renewal costs in a country's charging system may be due to the magnitude of the sums involved - renewal costs can easily double maintenance costs (UIC, 2004), or to their longer life cycle, which makes it more complicated to impose a levy for renewal costs on railway undertakings in the short term.

Often, however, the way national charging systems process maintenance and renewal costs has little to do with the nature of such costs. Considering that maintenance and renewal costs are directly related to a train's weight, at first glance it would seem that levying costs according to the methods that use the gross tonne-km (GTK) variable would be more realistic than the ones that use the train-km method.

However, the decision to use the GTK or train-km variable may also be due to policies to boost one type of traffic rather than another. This fact can be illustrated by making a simplified calculation of the charges converted into a common basis of $€ /$ train-km (data from the ITF-OECD (2008) report for Austria, Belgium, Bulgaria, Croatia, Czech Republic, Denmark, Estonia, Finland, France, Germany, Hungary, Italy, Latvia, Lithuania, Netherlands, Norway, Poland, Portugal, Romania, Slovenia, Slovakia, Spain, Sweden, Switzerland and the United Kingdom), and by taking into consideration an average weight for each type of train (920 tonnes for freight trains, 590 tonnes for long-distance passenger trains and 270 tonnes for regional and suburban trains, according to ECMT (2005)).

Next, calculate the freight/passenger charge ratio and compare it with the freight train/long-distance passenger train weight ratio. Thus, the countries whose charge ratio is higher than the weight ratios (equal to 1.63 in the above case) would be applying a higher pricing level to freight trains than to passenger trains, and therefore the former would be subsidizing the latter to a certain degree. Such is the case in Bulgaria, the Czech Republic, Finland, Latvia, Poland, Slovakia and Slovenia. All these countries (with the exception of Latvia) use the GTK variable in their pricing system, whether or not they may also use others, such as the train-km variable. This shows that they may be including weight in the charging parameter to justify higher levies on freight trains. Such cross-financing is obvious in former Soviet countries, where transporting goods by rail takes up such a large share of the market that most of the infrastructure costs are levied on freight trains.

If the charges ratio is compared to the weight ratio in longdistance trains and suburban trains (equal to $2 \cdot 19$ ), the charges ratio is found to be much lower than the weight ratio. This means that the suburban trains, which tend to be lighter than longdistance trains, are supporting a higher pricing level than their weight would imply. Moreover, other factors increase track wear and tear, such as speed and axle-load, which also tend to be lower in suburban trains than in long-distance trains. In many cases, this could be explained by the high subsidies granted to regional and suburban trains, which make them inelastic with regard to track charges. Using transport service subsidies to finance infrastructure may lead to mark-ups (surcharges set according to Ramsey pricing) related to the willingness to pay, which may be more due to the subsidies than to the cost or profitability of the train service. Such cross-financing may make infrastructure management and the railway undertakings' activities inefficient.

\section{Calculation of track maintenance and renewal costs}

Some European countries have carried out detailed studies to estimate the marginal costs of maintenance and renewal. In Finland, Austria, Sweden and Switzerland, the marginal costs were obtained by estimating a cost function and then proceeding to derive it with respect to tonnes-km (top-down approach). In the United Kingdom, a bottom-up method was used, starting with an analysis of the variations in cost caused by speed, axle load and unsprung mass per vehicle factor (Thomas, 2002).

Apart from the above methods, which require a complete database and costly studies, the simplest way to estimate a rail network's maintenance and renewal costs should be to start with the infrastructure manager's annual accounts. These data could be used to estimate the marginal costs, considering that, according 
to the above-mentioned studies, they amount to around $10-30 \%$ of the average maintenance and renewal costs. Actually, however, a series of deficiencies in the infrastructure manager's accounting methods tend to make them difficult to quantify.

(a) Aggregating maintenance and renewal costs to the operational costs of the network (traffic management, capacity management, administration costs and so on). The aggregation may be justified insofar as operation costs (i.e. signalling, traffic control and planning) and maintenance costs are running costs for the infrastructure manager, but whereas the former are practically fixed (95\% fixed, according to ORR (2005)), the latter are largely variable costs (up to $30 \%$, according to Thomas (2002)), and therefore processing them and subsequently levying them on railway undertakings should be done separately. Therefore, on the basis of the above, the operations costs should be estimated first, and then subtracted from the aggregate cost before proceeding to process the maintenance and renewal costs.

(b) Aggregation with enhancement and upgrading costs.

Enhancement and upgrading costs should be considered investment costs, since they mean adding new functionalities to existing infrastructure (enlargement of capacity, enhanced safety, and so on).

(c) Aggregation of track-related costs to electrification system costs (e.g. catenary and substations). Wear and tear and the costs generated by this subsystem are different for tracks, so they should be processed separately. Moreover, diesel trains have no reason to pay for the maintenance of the electrification system.

\section{Processing of maintenance and renewal costs}

Taking the interval of time between two renewals as a study period, the cumulated load on the track would make maintenance operations increasingly frequent and more important, whereas the quality of the track would diminish (Figure 1).

If traffic increases during the study period more than estimated and there is an attempt to keep the track up to a certain degree of quality (Figure 2, curve 1), the time interval between successive maintenance operations will diminish, and so will the life cycle of the renewal $(t)$. Therefore, the maintenance and renewal costs for a specific time interval will increase, in the same way that a decrease in traffic would have the contrary effect (Figure 2, curve 2).

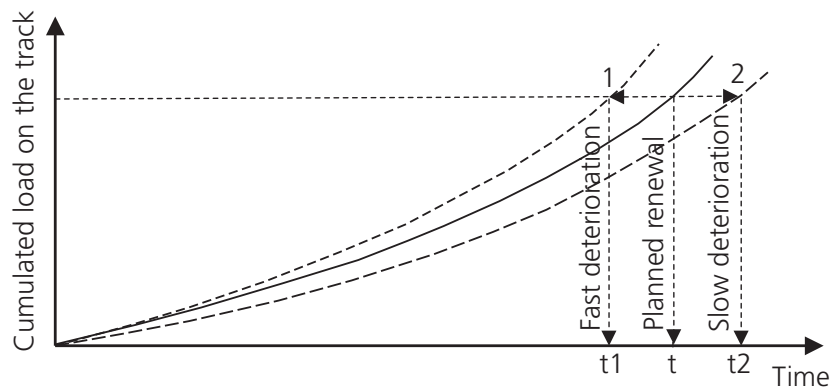

Figure 2. Traffic-related variation in the life cycle of maintenance and renewal operations. Source: own source, based on EPFL (2003)
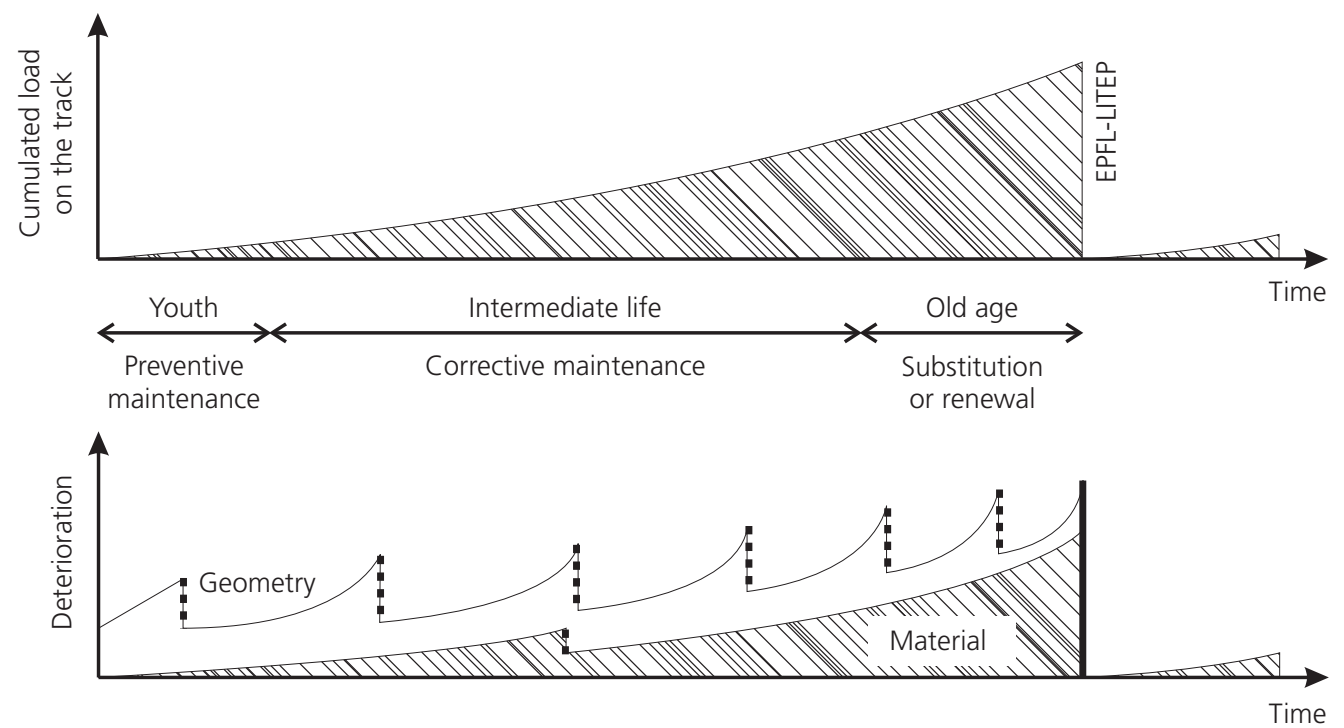

Maintenance actions ...... Renewal actions

Figure 1. Traffic-related maintenance and renewal operations.

Source: EPFL (2003) 
When processing the costs between two consecutive renewals (Figure 3), certain aspects should be taken into consideration.

(a) Planned preventive maintenance operations can be considered as costing the same ( $m_{\mathrm{p}}$ would be their annual cost).

(b) Renewal costs operations $(R)$ tend to be considerably higher than corrective maintenance costs operations $\left(M_{i}\right)$.

(c) The life cycle of corrective maintenance operations $\left(t_{i}\right)$ is shorter than the life cycle of renewal operations $(t)$, so $t_{i}<t$. Thus, $n$ correction maintenance operations are considered before the following renewal operation, so $t=\Sigma t_{i}$ where $i=0,1, \ldots, j, \ldots, n$.

(d) The more accumulated traffic on a track, the more and faster it deteriorates, and therefore maintenance costs increase throughout the track's life cycle.

(e) In practice, the renewal of a section of track is used as an opportunity not only to renew its parts, but also to replace them with higher quality parts (a heavier rail, rigid fastening by elastic fastening, wood sleepers by concrete sleepers, increased ballast thickness, and so on). That kind of renewal is known as an enhancement and upgrading operation. Enhancement and upgrading is more expensive than a mere renewal, but it may be justified because it helps to extend life cycle and to lower maintenance costs. For example, renewing a track with a UIC-71 rail instead of a UIC-60 rail, for instance, implies a $17 \%$ cost increase (Baumgartner, 2001). Moreover, if a technical progress clause exists, the renewal will go hand-in-hand with an enhancement.

According to the above, and considering a uniform distribution of costs throughout the life cycle of each operation (straight-line depreciation), costs will evolve as shown in Figure 4.

If this cost history were transposed directly to a railway undertaking, it would give an increasingly higher pricing level for track usage charges between two renewals. However, there are several factors that advise against using this pricing variable.

(a) Uncertainty with regards to the price of the charges arising from cost variation (much steeper towards the end of life cycle) would pose a barrier to railway undertakings right from the start.

(b) The utility of infrastructure to a railway undertaking evolves conversely (and, therefore, decreases) to the evolution of the cost involved. This is so because infrastructure provides the best conditions of strength and geometry when it is new. Moreover, tracks become less reliable and the increasing need for maintenance operations may make them less available as their life cycle advances, which could cause delays and capacity constraints.

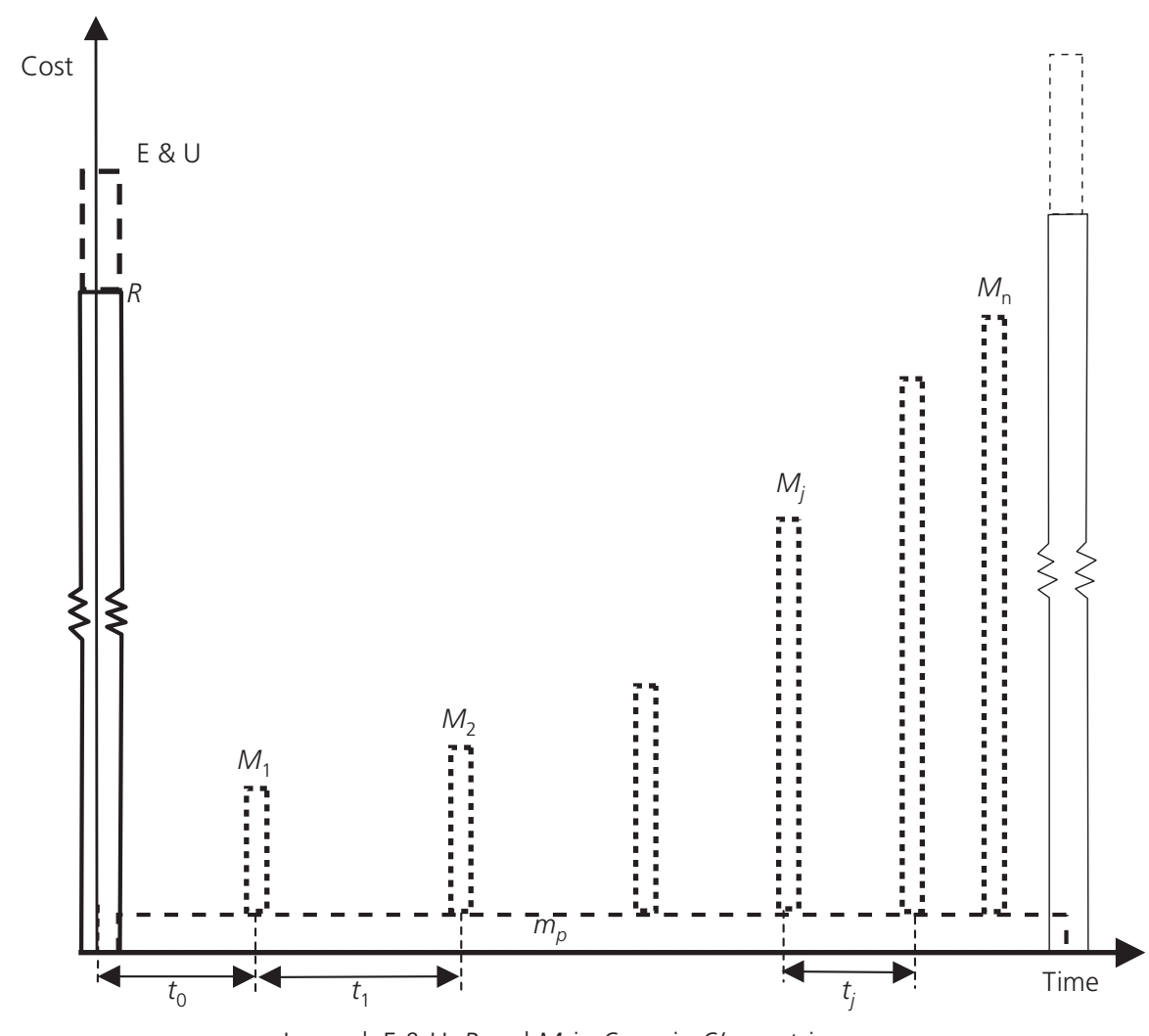

Legend: $E \& U, R$ and $M_{i}$ in $€ ; m_{p}$ in $€ /$ year; $t_{i}$ in years. 


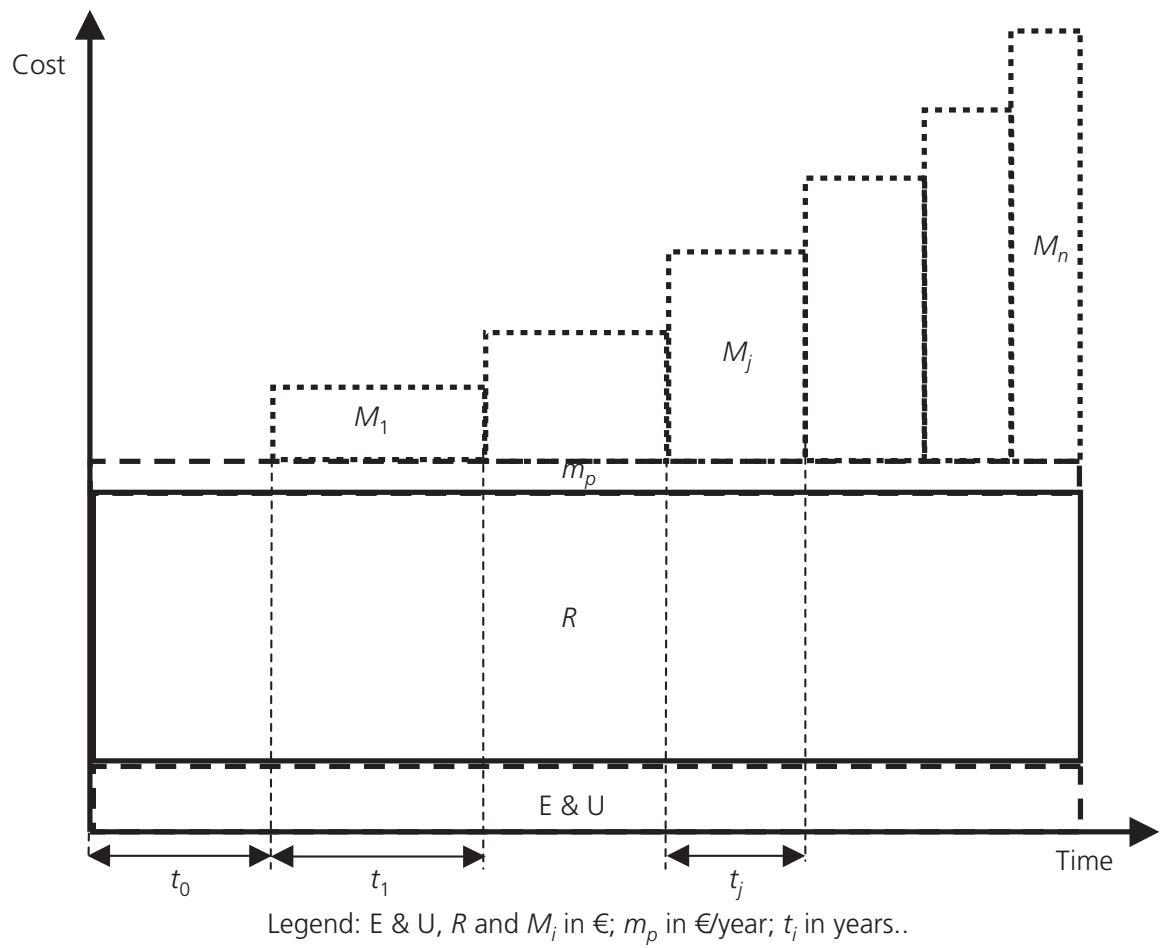

Figure 4. Evolution of costs between two renewals, uniformly distributed

Thus, taking utility into consideration, the pricing level between two renewals should diminish rather than increase. As a compromise that would reconcile the two conditioning factors (increasing charges and declining utility) and give a measure of stability to charges related to maintenance and renewal costs, this paper proposes a method in which cost distribution would be more balanced, as shown in Figure 5.

The cost distribution shown in Figure 5 has been obtained by adopting an accelerated depreciation method (e.g. sum-of-theyears'-digits method) for renewal cost $R$ and superimposing a uniform distribution of costs for maintenance operations $M_{i}$. An accelerated depreciation method charges higher amounts of depreciation in the earlier years and lower amounts in the later years of a fixed asset's life. Many assets (such as railway infrastructure) are more efficient and most useful when they are new, so a higher depreciation expense can be levied in those years. Over time, depreciation expense moves in a downward direction and maintenance costs tend to become higher (Siegel and Shim, 2005). Thus, by this proposal, the increase in maintenance costs towards the end of a track's life cycle is compensated by a reduction in the charges due to the renewal's depreciation. If enhancement and/or upgrading occur along with the renewal, the associated increase in cost should be treated separately, as explained in Section 5, and therefore it is not given in Figure 5.

Currently, RAILCALC (CENIT, TIS PT, IWW and HERRY, 2008) and similar projects are recommending ABC (activity based costing) to levy the marginal operational costs (i.e. maintenance, renewal, and signalling). As for cost assessment, the RAILCALC project recommendation is to consider a dynamic forward-looking approach to current and future costs, better than historical costs. The reason for this approach lies in the fact that considering current and planned costs in relation to the estimated level of service and production can be an incentive to improve infrastructure management.

As an aid to implementing the $\mathrm{ABC}$ method, a more stable level of pricing would be attained in the middle term with the cost distribution shown in Figure 5 (with regards to the uniform distribution of costs shown in Figure 4), which is based on actual and estimated costs. Moreover, the method proposed would also allow a closer relationship between the pricing level and the quality of service given to the operator, so the charges obtained would be more market-oriented. The steps needed to arrive at the proposed cost distribution are given below. Treatment of the renewal costs requires middle and long-term planning.

1. $R$, renewal cost. A given datum, since it is an operation that marks the beginning of the analysis period.

2. $t$, life cycle of the renewal. Historical data need to be used for estimating this time interval. Values in Table 1 could be used as reference.

3. Distribute the renewal cost according to a decreasing depreciation method based on $R$ and $t$. 


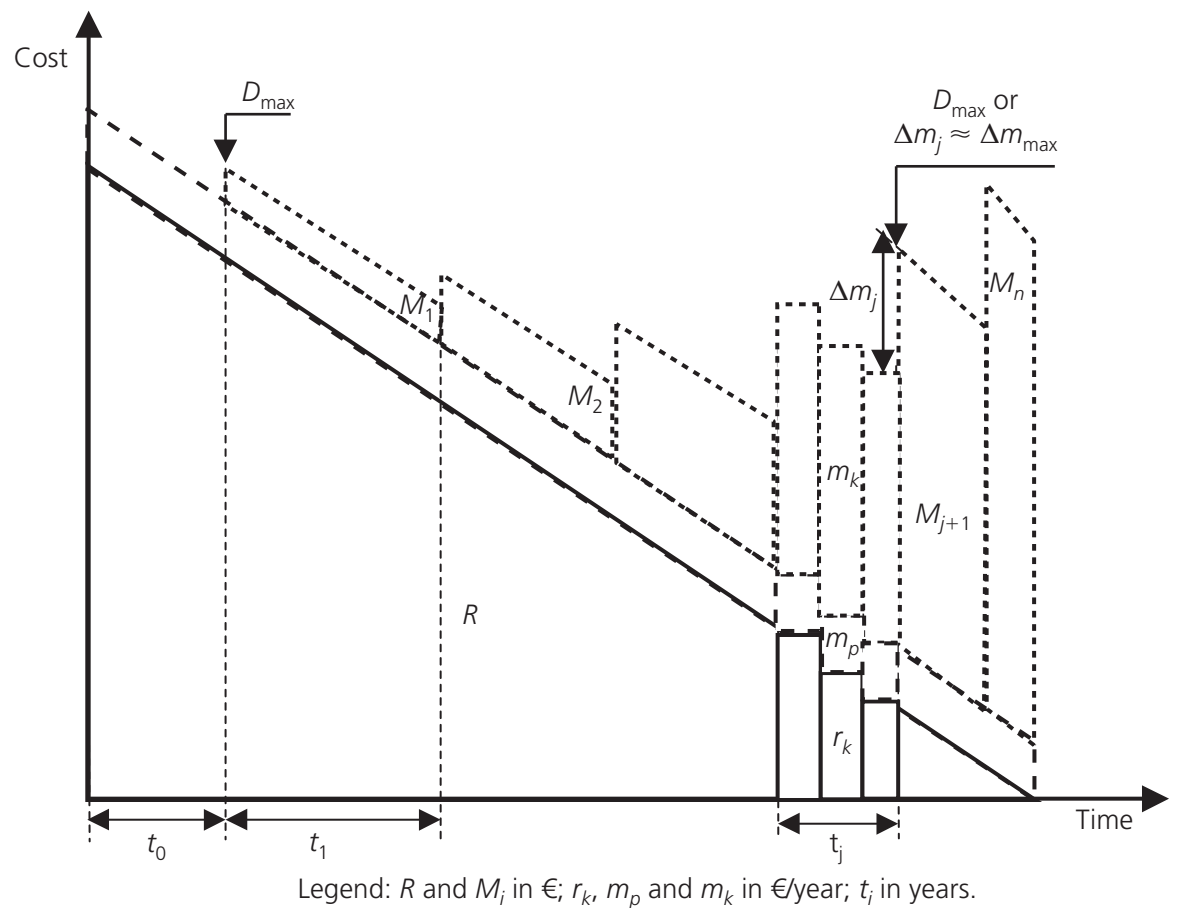

Figure 5. Proposal for cost depreciation between two renewals

Traffic (single track)

\begin{tabular}{lcccc}
\hline$\times 10^{3}$ GTK/day & 10 & 30 & 100 & 300 \\
$\times 10^{6}$ GTK/day & $2 \cdot 5-3.6$ & $7 \cdot 5-11$ & $25-36$ & $75-108$ \\
\hline
\end{tabular}

Track with rail: $\quad$ Life cycle of the renewal: years

\begin{tabular}{lcccc}
\hline UIC 54 & 40 & 20 & 10 & - \\
UIC 60 & - & 25 & 12 & 6 \\
UIC 71 & - & - & - & 7 \\
\hline
\end{tabular}

GTK, gross tonne-kilometre.

Table 1. Life cycle of a renewal operation. Source: Baumgartner (2001)

Maintenance costs require short-term planning.

1. The annual cost of preventive maintenance $\left(m_{\mathrm{p}}\right)$ can be easily predicted according to the diagnosis and inspection jobs that have been planned.

2. Setting a track quality standard, associated with a maximum deterioration allowed $\left(D_{\max }\right)$.

3. The first corrective maintenance operation $(i=1)$ should be performed when track deterioration approaches $D_{\max }$. The maintenance operation's useful life $\left(t_{1}\right)$ ends when a new $D_{\max }$ is attained. The operation's real cost $\left(M_{1}\right)$ and its useful life can be used to calculate the annual cost:
1. $m_{1}=M_{1} / t_{1}$

From this datum (or from any $m_{i}$ ) the annual maintenance cost for subsequent periods can be estimated following the steps described below.

4. The maintenance cost in subsequent periods can be estimated according to how it develops in comparison with the previous cost, based on the evolution of traffic during the current period. The theoretical traffic load (Figure 6) may be used to estimate how much maintenance costs will vary with the level of traffic. This concept, which relates a train's key 


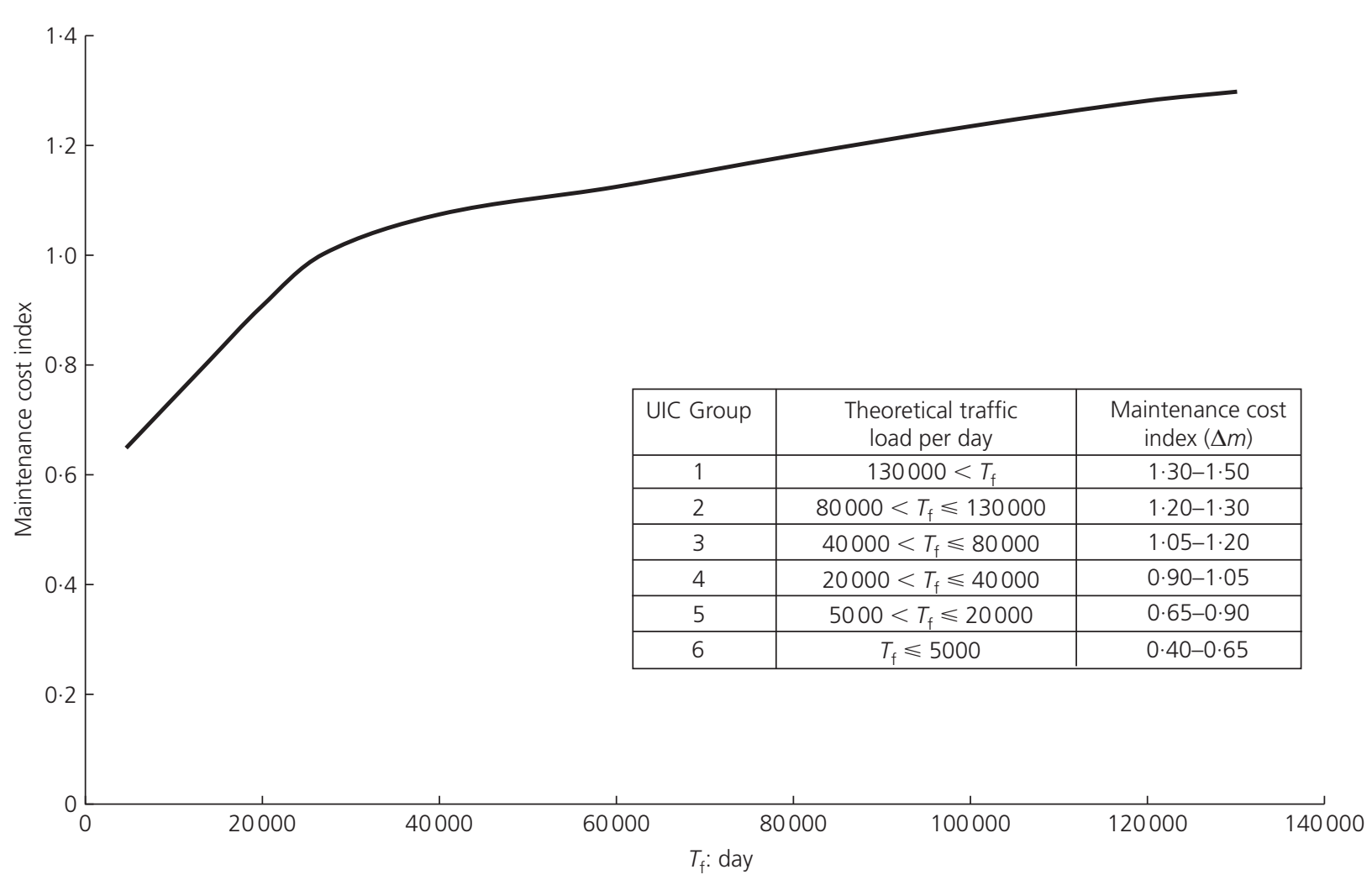

Figure 6. Variation of annual maintenance cost with the theoretical traffic load. Source: own source, based on UIC (1992)

features to maintenance costs, and the corresponding cost studies were developed by the UIC's Way and Works group (UIC, 1989, 1992). The variation of the annual cost of maintenance $(\Delta m)$ as compared with the development of the theoretical traffic load can be obtained from Figure 6 .

From Figure 6 it can be inferred that if increases in traffic are related to the growth in costs, the latter will increase more slowly at higher traffic levels. That implies that the cost per unit of maintenance decreases with the level of traffic. This is characteristic of railway infrastructure, which moves in the area of growing average yields.

Thus, the estimated maintenance cost for the following period is obtained by multiplying the variation (taking the Index in Figure 6) by the cost of the previous period.

2. $m_{j+1}=m_{j}^{*} \Delta m_{j}$

where the maintenance cost variation is based on how traffic evolves:

3. $\Delta m_{j}=f\left(\Delta T_{\mathrm{f}} / d a y\right)_{j}$
The estimated life cycle for the next period $\left(t_{j+1}^{\mathrm{e}}\right)$ would be given by:

$$
\text { 4. } \quad t_{j+1}^{\mathrm{e}}=M_{j+1} / m_{j+1}
$$

where $M_{i}(i=1,2, \ldots, j, j+1, \ldots, n)$ is the emerging real cost of each maintenance operation.

5. The real life cycle of each one of the operations $\left(t_{j}\right)$ will be given by one of two conditions:

(i) Deterioration close to $D_{\max }$.

(ii) An increase in maintenance costs up to a value close to the maximum acceptable value $\left(\Delta m_{j} \approx \Delta m_{\max }\right)$.

6. To determine the last maintenance operation before the next renewal, an associated cost limit $\left(M_{n}\right)$ needs to be set.

Thus, the annual cost associated to maintenance and renewal operations during any ' $k$ ' year $\left(r_{k}+m_{\mathrm{p}}+m_{k}\right)$ for the period of time concerned is obtained (Figure 5).

In Figure 5, the end of the renewal's life cycle coincides with the end of the last maintenance operation's life cycle. In other words, the renewal has been amortised by the end of the track's life cycle. If this forecast is not met, adjustments can be made in two cases. 
(a) Case 1: track deterioration sooner than forecasted $\left(M_{n}\right.$ is reached before getting to $t$ ). The renewal cost that remains to be amortised may be carried over to the next period.

(b) Case 2: track deterioration is slower than estimated (the renewal is amortised before $M_{n}$ is reached). In this case, the pricing level of the track usage charges at the end of the track's life cycle could be lowered, or a minimal pricing for renewal costs, to be discounted in the next period, could be considered.

Similar corrections need to be made for any maintenance operations whose useful life does not match the estimated life $\left(t_{j}^{\mathrm{e}} \neq t_{j}\right)$.

\section{Levying maintenance and renewal costs}

A top-down method that takes into account the main cost drivers may be used to levy maintenance and renewal costs. Maintenance and renewal costs increase with static and dynamic loads on the track, and also according to a line's characteristics. Thus, with regards to a train's features, the maintenance and renewal costs show the following activities.

(a) Increase with the train's total weight, since heavier trains cause higher loads on the track.

(b) Increase with a train's axle-load. Therefore, self-propelled trains, being lighter than conventional trains, cause lower maintenance and renewal costs because their traction tends to be more distributed, making their maximum load per axle lighter.

(c) Increase with unsprung mass, whose weight has a direct, unmitigated impact on the track, thereby increasing the dynamic loads.

(d) Diminish when the suspension system is improved (by installing pneumatic suspension, for instance).

(e) Increase with traffic speed, because dynamic loads increase with traffic speed.

With regard to lines, the maintenance and renewal costs show the following activities.

(a) Diminish with improvements to the line's layout. More moderate gradients and wider curves diminish lengthwise and crosswise stress on tracks.

(b) Diminish with the strength of the track. Heavier rails, concrete sleepers, ballast border thickness of more than $30 \mathrm{~cm}$ and better quality subgrade increase track strength as a whole, so train traffic causes less wear and tear.

(c) Increase with the infrastructure's age, since maintenance operations are more frequent. Old tracks are more prone to deformations that increase dynamic loads, which in turn accelerate wear and tear.

(d) Increase in high-speed lines, for daily inspection and maintenance operations to ensure security when running at high speeds increase maintenance costs (Baumgartner, 2001).
In European charging systems, basic parameters (train-km and GTK) are used to levy maintenance and renewal costs. Sometimes other aspects are also considered, such as speed, axle-load, train type, traffic type (mainly passenger/freight) and the quality of the infrastructure (normally, the price increases with the quality of the infrastructure).

However, price modulation is not always transparent. It does not show how variations in price are calculated and it gives rise to fixed prices at intervals, which may cause distortions in the market. Instead of the price modulation option, authors suggest starting with the cost for each type of line (namely high speed, lines upgraded for high speed or conventional lines) and levying charges according to a simple formula that reflects the trains key wear and tear related features (weight, speed and axle-load).

To do so, the wear and tear caused by each train could be related to the theoretical traffic load $\left(T_{\mathrm{f}}\right)$ it generates (UIC, 1989).

$$
\text { 5. } T_{\mathrm{f}}=S^{*}\left(T_{\mathrm{v}}+K_{\mathrm{t}}^{*} T_{\mathrm{tv}}\right)+S^{*}\left(K_{\mathrm{m}}{ }^{*} T_{\mathrm{m}}+K_{\mathrm{t}}{ }^{*} T_{\mathrm{tm}}\right)
$$

where $S$ is the coefficient that increases from 1.00 for speeds under $60 \mathrm{kph}$ up to 1.50 for speeds above $250 \mathrm{kph}$ it takes into account that dynamic loads increase the static loads up to $50 \%$ when speed increases (Prud'homme, 1970); $T_{\mathrm{v}}$ is the weight in tonnes of the passenger cars; $K_{\mathrm{t}}$ is the coefficient allowing for the traction-motor axle wear factor, and is equal to $1.40 ; K_{\mathrm{m}}$ is the coefficient allowing for the influence of the axle-loads of freight wagons. Increases from 1.15 to 1.45 with the axle-load. The $K_{\mathrm{t}}$ and $K_{\mathrm{m}}$ coefficients take into account the effects of the weight of the train's axles (static loads). They adopt maximum values for heavy vehicles (for example, locomotives and heavy loaded wagons with axle-loads of 20 tonnes or more) and lower values for light vehicles (for example empty or partially loaded wagons with axle load under 20 tonnes); $T_{\mathrm{tv}}$ weight in tonnes of the tractive unit, in passenger trains; $T_{\mathrm{m}}$ gross tonnes hauled, in freight trains; $T_{\mathrm{tm}}$ weight of the locomotive in freight trains.

Passenger multiple units with concentrated traction (normally, axle-loads of more than 17 tonnes) may be included in the tonnage of tractive units $\left(T_{\mathrm{tv}}\right)$, whereas lighter multiple units with more distributed traction (usually, axle-load of less than 17 tonnes) should be included in $T_{\mathrm{v}}$.

The variables on which $T_{\mathrm{f}}$ depends can be easily known to the railway undertaking and the infrastructure manager, since speed can be considered the average speed and $K_{\mathrm{m}}$ will depend on the load transported by the train.

Using this parameter requires turning traffic (i.e. train- $\mathrm{km}$ or GTK) into notional traffic $\left(T_{\mathrm{f}}-\mathrm{km}\right)$, finding the equivalence of each train in $T_{\mathrm{f}}$ and multiplying the result by the distance covered. The process can be simplified by using the more typical trains. 


\section{Offprint provided courtesy of www.icevirtuallibrary.com Author copy for personal use, not for distribution}

To meet the aims of cost adjustment, data availability and charging system simplification, marginal costs can be levied on the basis of their share of the total cost, instead of calculating a cost function, with the difficulty and relative degree of closeness to reality that implies, or carrying out a study of bottom-up costs.

The average cost $\left(€ / T_{\mathrm{f}}-\mathrm{km}\right)$ can be obtained by dividing the annual maintenance and renewal costs $\left(r_{k}+m_{\mathrm{p}}+m_{k}\right)$ for a line (or a network, if no cost breakdown is available) by the annual theoretical traffic. Next, multiplying the average cost by the $T_{\mathrm{f}}$ equivalent for each train will give the total traffic-related cost of each train $(€ / \mathrm{km})$, and therefore a closer idea than the train-km or GTK (Calvo et al., 2007). Having obtained each traffic-related cost, the pricing level can be set between the marginal costs (taking around $20 \%$ of the total cost) and the total cost (considering such aspects as the railway undertaking's willingness to pay). Figure 7 outlines the processing and levying of track costs.

\section{Processing upgrading and enhancement costs}

As mentioned in Sections 2 and 3, track renewal is often used as an opportunity for enhancement or upgrading or, conversely, maintenance and renewal costs are added to the cost for enhancement and renewal. In either case the extra costs need to be considered as an investment and the share for upgrading needs to be estimated. Next, a decreasing depreciation method can be used to distribute the cost of enhancements and upgrades along their life cycle. To finish, mark-ups can be used to recover upgrading and enhancement costs (fixed costs) according to each railway service's real willingness to pay (and thus, discounting public service grants). The real ability to pay is directly related to the profit obtained from each railway service. However, it is also obvious that railway undertakings will not be very willing to provide a breakdown of income and expenditure in a competitive environment. Therefore, this paper proposes applying mark-ups as listed here.

(a) Via a charge that is separate from maintenance and renewal charges.

(b) According to the railway undertaking's willingness to pay, in view of potential profit estimated on the basis of the service's features (i.e. seats-km and speed) and the quality of the line used.

(c) Taking into account the estimated increase in profits of the railway undertaking accruing from the upgrade.

(d) In situations of congestion, mark-ups can also be modulated according to the willingness to pay for a certain train-path. The willingness to pay for a train-path is related to the opportunity cost, which increases with demand (level of congestion), adjustment of the allocated path to the train-path requested, priority and so on.

The latter three aspects (service features, infrastructure quality and train-path-related opportunity cost) are directly related to railway undertakings' potential profit and, therefore, to their ability to pay. Thus, the three aspects of pricing are market-oriented and give room to hope that some of the fixed costs will be recovered.

\section{Conclusion and recommendations}

Infrastructure managers need to distinguish between operation costs and asset-related costs if they are to contribute to charging system transparency. Asset-related costs should make a distinction between investment cost items (including construction, upgrading and enhancement) and maintenance and renewal for the different railway sub-systems (infrastructure, electrification, signalling, etc.).

A study of current charging systems in Europe leads to the conclusion that using the parameters that best reflect the causeeffect relationship between wear and tear and the cost incurred is not enough to adjust the charging system to costs. It also requires the non-existence of crossed-financing between railway services.

A constant depreciation of maintenance and renewal costs gives a growing distribution of costs, with the increase being much larger towards the end of the track's service life. However, when levying the track costs on railway undertakings between two renewals should take into consideration that the track's utility for the operator diminishes towards the end of its service life (as does the quality of the track and due to the fact that the frequency of maintenance operations increases, which in turn makes the infrastructure less available and may cause delays and lack of capacity).

Therefore, when faced with the dilemma posed by an increasing pricing level (due to increased maintenance costs) and a decreasing pricing level (in relation to utility), this paper proposes a method that provides for a more uniform distribution of track related costs between two renewal operations (compared with using an overall uniform distribution of costs). The method consists in distributing the cost of renewal according to a decreasing depreciation method and superimposing the cost of maintenance on it, uniformly distributed.

With the proposed method, the track charge gains stability in the middle term, which provides an incentive for new railway undertakings entering the market, since the estimated useful life of railway rolling stock is 25 years, similar to the depreciation period of renewal operations. The track charges are also more market-oriented, because they take the utility perceived by the railway undertaking into account.

Moreover, because it is based on the current and forward-looking costs for track expenses, the proposed system could be of use in implementing an $\mathrm{ABC}$ method. Costs should be planned according to the track's standard of quality and the UIC's concept of theoretical traffic load.

In Europe, the current practice is to use simple parameters to levy track usage charges (train-km, GTK), occasionally modulating 


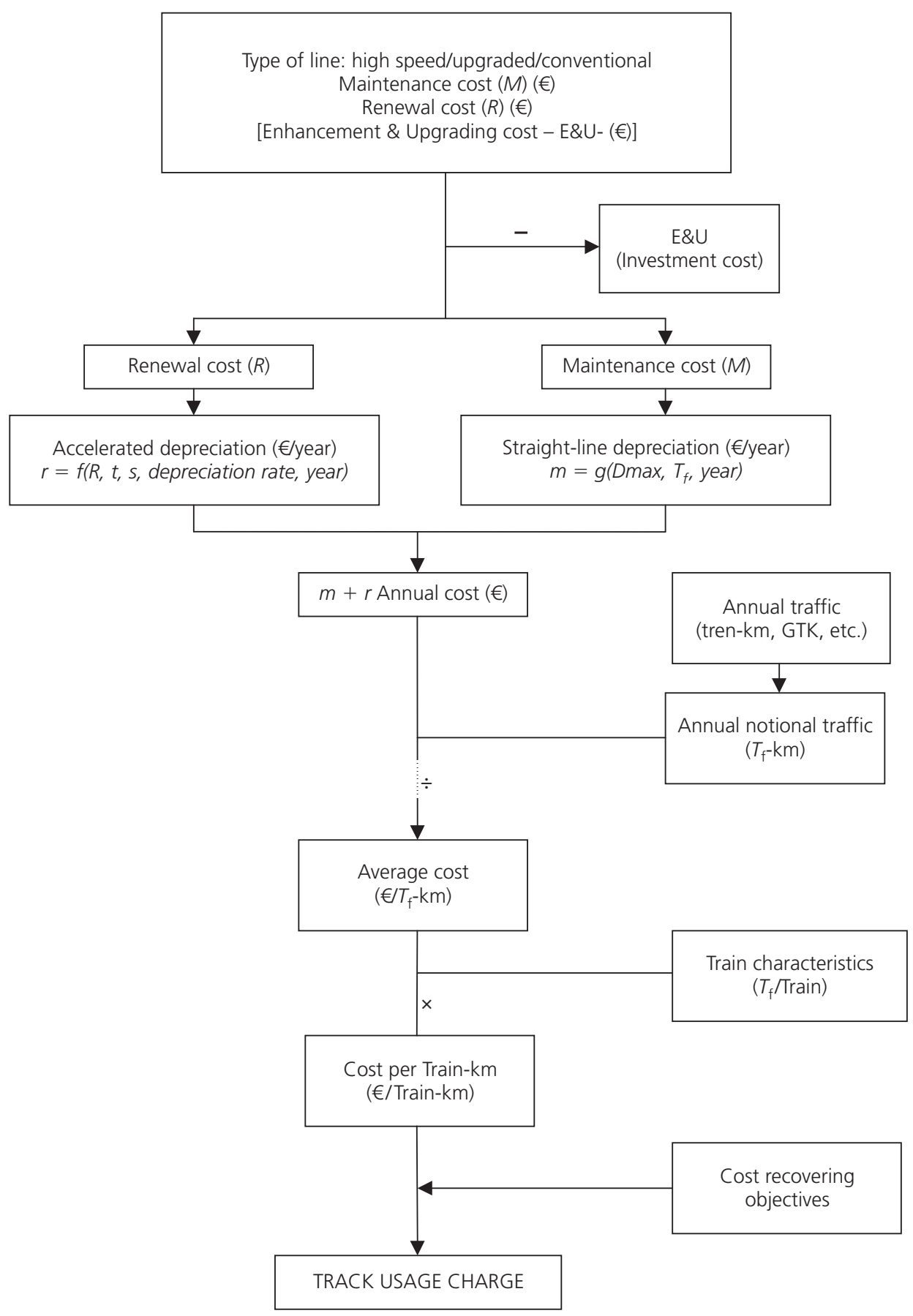

Figure 7. Cost processing and calculation of track usage charge

prices according to several aspects, such as speed, train type, and traffic type. Normally, several different costs are included in a single track charge (e.g. maintenance, administrative costs, signalling and traffic planning). This method is not transparent and may cause distortions on the market.

In view of this situation, this paper proposes using a dedicated charge to levy track usage charges. As a simplified method of calculation, this paper recommends taking the cost according to line type (mainly high speed/upgraded/conventional) and using a top-down approach based on a levying parameter that includes key cost-drivers. The parameter proposed is the theoretical traffic load, which relates each trip with the cost generated and, therefore, it also contributes to prevent cross-financing between 
railway services. Using a single item (theoretical traffic load) to plan costs and transfer them to the railway undertakings helps to simplify track charge processing.

After calculating the total annual track cost, the price of the track usage charge can be set between the marginal cost and the total cost, according to the objectives of cost recovery. The increase in prices over the marginal costs should be set on the basis of the real ability to pay each railway service, thereby preventing transport service subsidies from being used to subsidise infrastructure and crossed financing between services. Whether or not mark-ups should be applied will depend on the nature of some railway services as a public service and their contribution to the transport systems sustainability. The economic assessment of the above factors should be taken into consideration when subsidising the costs not covered by the infrastructure manager.

\section{REFERENCES}

Baumgartner JP (2001) Prices and costs in the railway sector. Laboratoire d'Intermodalité des Transports et de Planification. École Polytechnique Fédérale de Lausanne. See http://litep.epfl.ch (accessed 07/03/2007).

Calvo FJ, de Oña J and Nash A (2007) Proposed infrastructure pricing methodology for mixed-use rail networks. Transportation Research Record 1995: 9-16.

CENIT, TIS PT, IWW and HERRY (2008) RAILCALC. Calculation of charges for the use of rail infrastructure. European Commission. Directorate General for Energy and Transport. See http://yoda.upc.es (accessed 17/11/2008).

ECMT (European Conference of Ministers of Transport) (2005) Charges for the use of infrastructure in ECMT railways
(Draft final report). ECMT/CS/CF(2005)1/REV1. See http:// web.worldbank.org (accessed 23/06/2006).

EPFL (Ecole Polytechnique Féderale de Lausanne) (2003) IMPROVERAIL: IMPROVEd tools for RAILway capacity and access management. See http://litep.epfl.ch (accessed 25/02/2006).

ITF-OECD (International Transport Forum-Economic Co-operation and Development) (2008) Charges for the use of rail infrastructure 2008. See http://www. internationaltransportforum.org (accessed 03/03/2009).

ORR (Office of Rail Regulation) (2005) Review of Variable Usage and Electrification Asset Usage Charges: Final Report. ORR, London, UK. See http://www.rail-reg.gov.uk (accessed 19/09/2007).

Prud'homme A (1970) La Voie. RGCF, Paris, France.

Siegel JG and Shim JK (2005) Dictionary of Accounting Terms. Barron's Educational Series, New York, NY, USA.

Thomas J (2002) EU Task Force on Rail Infrastructure charging: summary findings on best practice in marginal cost pricing. IMPRINT-EUROPE. Implementing Reform in Transport. Effective Use of Research on Pricing in Europe. An European Commission funded Thematic Network (2001-2004). See http://www.imprint-eu.org (accessed 01/10/2006).

UIC (International Union of Railways) (1989) Classification of lines for the purpose of track maintenance. Leaflet $714 \mathrm{R}$, UIC, Paris, France.

UIC (International Union of Railways) (1992) Factors affecting track maintenance costs and their relative importance. Leaflet 715 R, UIC, Paris, France.

UIC (International Union of Railways) (2004) Lasting infrastructure cost benchmarking (LICB). Summary Report. October 2004. See http://www.uic.org (accessed 11/09/2005).

\footnotetext{
WHAT DO YOU THINK?

To discuss this paper, please email up to 500 words to the editor at journals@ice.org.uk. Your contribution will be forwarded to the author(s) for a reply and, if considered appropriate by the editorial panel, will be published as a discussion in a future issue of the journal.

Proceedings journals rely entirely on contributions sent in by civil engineering professionals, academics and students. Papers should be 2000-5000 words long (briefing papers should be 1000-2000 words long), with adequate illustrations and references. You can submit your paper online via www.icevirtuallibrary.com/content/journals, where you will also find detailed author guidelines.
} 